\title{
ANALISIS A DEBT-FOR-NATURE SWAP SEBAGAI ALTERNATIF MENGURANGI UTANG INDONESIA PADA LUAR NEGERI
}

\author{
Hinsa Siahaan ${ }^{1}$
}

\begin{abstract}
Given the size of Indonesia's foreign debt and the rate of forest destruction, "a debt-for-nature swaps" seems an obvious solution. In these schemes, a portion of a nation's public debt is bought by a third party at substantial discount. The debt then is cancelled. In return, the country promise to protect severall million hectares of forests. This research focused on dicussion of the possibility of the Government of The Republic of Indonesia to reduce its foreign debt by using a debt-for-nature swap.
\end{abstract}

Keywords: a debt-for-nature swaps, debt, Indonesia

ABSTRAK
Melihat utang Indonesia kepada negara asing dan banyaknya perusakan hutan,
"a debt-for-nature swaps" terlihat sebagai solusi yang jelas untuk mengatasi masalah
tersebut. Rencananya adalah, sebagian utang Indoensia dibeli oleh pihak ketiga dengan
diskon khusus. Utang Indonesia kepada negara asing itu kemudian dibatalkan. Sebagai
gantinya, negara berjanji untuk melindungi beberapa ribu hektar hutan yang ada.
Penelitian ini terfokus pada diskusi kemungkinan pemerintah Republik Indonesia untuk
mengurangi utang luar negerinya dengan "a debt-for-nature swaps".
Kata kunci: a debt-for-nature swaps, utang, Indonesia

${ }^{1}$ Staf Pengajar Fakultas Ekonomi Jurusan Manajemen, UBiNus, Jakarta

Analisis a Debt-For-Nature Swap ... (Hinsa Siahaan) 


\section{PENDAHULUAN}

Pembangunan di negara dunia ketiga, termasuk Indonesia, yang tidak mungkin dilakukan tanpa investasi besar-besaran (the big push theory) telah mendorong pemerintah orde baru untuk membuka kran selebar-lebarnya untuk modal asing dari luar negeri untuk diinvestasikan di Indonesia. Dari sejak repelita pertama 1969/70-1973/74 hingga repelita berikutnya, bahkan setelah pemerintah orde baru digantikan oleh pemerintah reformasi sekarang ini, pemerintah senantiasa menggunakan dana bantuan negara asing sebagai salah satu komponen pembangunan ekonomi. Akibatnya, tidak mengherankan jika sekarang ini Indonesia telah dibebani dengan utang luar negeri yang jumlahnya terus membengkak sehingga pemerintah mengalami kesulitan untuk melunasi tidak hanya pokok pinjaman tetapi juga bunga pinjaman setiap kali tiba jatuh tempo.

Utang yang jumlahnya sangat besar dan masih cenderung bertambah besar di masa yang akan datang telah mempersulit pemerintah untuk melakukan pembangunan ekonomi. Dana yang semakin terbatas karena harus membayar cicilan bunga dan pokok pinjaman membuat pemerintah terkendala dalam membiaya kebutuhan rutin dan kesulitan dalam membiayai pembangunan. Padahal, dana untuk belanja barang modal dalam jumlah sangat besar mutlak diperlukan untuk menciptakan kesempatan kerja dan menciptakan nilai tambah demi kesejahteraan rakyat Indonesia. Memang, mungkin saja pemerintah 'ngemplang' (tidak membayar) utang kepada luar negeri, tetapi itu tentunya akan menurunkan reputasi dan menghancurkan kedaulatan Indonesia di mata dunia internasional. Permasalahannya, apakah ada pilihan untuk mengurangi utang Indonesia kepada negara asing yang cenderung meningkat selama ini?

Ada yang berpendapat bahwa pengurangan utang luar negeri Indonesia dapat dilakukan dengan swap (a debt-for-nature swap). Namun, pendapat lain mengatakan pelunasan utang dengan swap lazimnya hanya dilakukan oleh pihak swasta, oleh perusahaan multinational corporation, tidak lazim oleh suatu negara yang berdaulat seperti Negara kita Republik Indonesia tercinta ini. Ada yang pesimis ada juga yang optimis melihat swap sebagai salah satu alternatif untuk mengurangi beban utang Indonesia kepada luar negeri. Hal itu dapat dibaca pada media massa, seperti dikutip berikut ini.

“Debt Swap tak efektif.” Pengurangan utang melalui mekanisme debt swap dinilai belum cukup efektif mengurangi beban utang luar negeri. Deputi Direktur Internasional NGO Forum on Indonesian Development (Infid), Dian Kartika Sari, mengatakan dalam sejarah utang dunia, besar utang yang dikonversi dalam debt swap (sebagian utang yang dialihkan sesuai kesepakatan kreditor dan debitor, biasanya untuk pembangunan fasilitas sosial Negara bersangkutan) hanya $10 \%$ dari total pokok utang dan bunga yang harus dipikul debitor. "Debt swap itu terlalu sedikit dan terlalu minim. Sedapat mungkin pemerintah harus mengusahakan mekanisme debt cancellation (pembatalan utang) atau debt cut (pemotongan utang)", tuturnya kepada pers, kemarin.” (Bisnis Indonesia, Jumat 13 Januari 2006). 
“Potensi penerimaan Debt Swap US\$500 juta” Pemerintah berpotensi mendapatkan dana sekitar US\$ 500 juta per tahun dari program debt swap (konversi pembayaran utang luar negeri untuk pembiayaan program tertentu di dalam negeri atas persetujuan kreditor), asalkan dapat melobi parlemen di negara kreditor yang belum memberikan fasilitas ini. Sebab itu, pemerintah perlu dibantu oleh parlemen untuk melobi parlemen negara yang tidak memiliki fasilitas tersebut.

Mantan Menko Perekonomian, Dorodjatun Kuntjoro Jakti, di sela-sela Rapat Kerja Persatuan Perusahaan Air Minum Seluruh Indonesia di Jakarta, akhir pekan lalu mengatakan, guna mendapatkan fasilitas debt swap, pemerintah dapat memanfaatkan isu Millenium Development Goals atau pencapaian tujuan milennium serta alasan, seperti jumlah penduduk besar. Dia mengatakan, hingga saat ini baru baru negara Eropa yang memiliki fasilitas debt swap. Negara lain, seperti Jepang yang menjadi kreditor terbesar Indonesia, tidak dapat memberi fasilitas itu karena tidak diperbolehkan Undangundangnya. "Pentingnya menggalang lobi antarparlemen karena parlemen di masingmasing negara memiliki kewenangan untuk memutuskan persoalan keuangan negara," kata Dorodjatun (Suara Pembaruan, Senin 16 Januari 2006).

\section{PEMBAHASAN}

Terlepas dari pro-kontra atau terlepas dari sikap pesimis dan optimis bahwa swap dapat digunakan mengurangi atau melunasi utang luar negeri, kajian berikut ini adalah untuk membahas sejauh mana swap agreement atau a debt-to-nature swap dapat digunakan secara efektif untuk mengurangi utang Indonesia kepada pihak luar negeri. Untuk itu, pembahasan dimulai dari riset literatur mengenai pengertian debt swap secara teoritis, diikuti dengan pembahasan pengertian debt natural swap dikaitkan dengan isu millennium development goals. Dilanjutkan dengan kajian penggunaan debt swap berdasarkan pengalaman negara lain, dan analisis kemungkinan penggunaan debt swap untuk melunasi utang Indonesia. Terakhir tetapi tidak kalah pentingnya, kajian ini diharapkan menghasilkan rekomendasi yang dapat digunakan para pengambil keputusan sebagai input untuk merumuskan kebijaksanaan (policy) penanggulangan utang luar negeri Indonesia.

Sumber utama data kualitatif, berupa konsep atau kerangka teoritis yang digunakan dalam kajian ini adalah berbagai literatur yang ditulis oleh para pakar luar negeri maupun pakar dari dalam negeri. Selain riset literatur, penulis juga menggunakan media cetak dan media elektronik internet sebagai sumber data. Khusus untuk data kuantitatif, digunakan publikasi Departemen Keuangan dan Bank Indonesia sebagai sumber utama. Pada dasarnya, data yang digunakan dalam kajian ini adalah merupakan data sekunder dan merupakan public information yang dapat diperoleh umum. Dalam dunia bisnis, terutama yang bergerak antarlintas negara yang menggunakan beragam mata uang, penggunaan swap banyak digunakan untuk menghindari risiko. Bukan hanya risiko 
tingkat suku bunga (interest risk) tetapi juga risiko kurs (exchange risk). Dua macam swap yang dominan digunakan dalam bisnis antarlintas negara adalah swap dikaitkan tingkat bunga di masa yang akan datang menggunakan mata uang tunggal dan swap mata uang dengan tingkat bunga dan mata uang lebih dari satu macam.

Pengertian umum swap adalah perjanjian (kesepakatan) secara legal antara dua pihak yang masing-masing pihak akan saling membayarkan sejumlah uang kepada pihak lain tetapi tergantung kondisi ekonomi yang terjadi di masa yang akan datang. "As it its name imples, a swap is normally defined as an exchange. More specifically, it is an exchange of cash flow over time between two parties (generally referred to as the "counterparties"). ${ }^{2}$

Steven L. Allen, Arnold D.Kleinstein (1991) mengatakan: "the two predominant types of swap are known as:

1. Interest rate swaps in which the payments are tied to future interest rates within a single currency (e.g. U.S. dollar interest rate), and

2. Currency exchange agreements in which payments are determined by both interest rates and foreign exchange rates between two different currencies. ${ }^{3}$

Faktor motivasi yang melatarbelakangi pembentukan pasar swap adalah bahwa dua pihak atau dua lembaga keuangan akan sama-sama mendapatkan keuntungan karena salah satu pihak memiliki kelebihan/keunggulan relatif dalam mendapatkan dana dari dua pasar yang berbeda. Pendorong utama timbulnya pasar swap adalah hasrat untuk mengisolasikan risiko kredit dari risiko ekonomi lainnya, seperti perubahan tingkat suku bunga dan perubahan kurs mata uang asing.

Hamdy Hady (1998) mendefinisikan swap sebagai suatu kontrak transaksi pembelian atau penjualan valas dengan spot rate yang dikombinasikan dengan pembelian atau penjualan valas yang sama dengan forward rate (J.O. Grabbe, 1996:313) dan mengatakan bahwa: "dalam praktkiknya di pasar atau di bursa valas internasional, transaksi swap ini dilakukan dalam berbagai bentuk, yaitu currency swap, interest rate swap, cross-currency interest rate swap, dan swaptions." Swap yang dikemukakan adalah yang lazim digunakan oleh perusahaan multinational dan lembaga keuangan swasta yang beroperasi antarlintas negara. Bagaimana dengan a debt-for-nature swap? Siapakah pelakunya?

Ternyata a debt-for-nature swap telah dilakukan oleh negara sedang berkembang (negara dunia ketiga) sejak tahun 1980'an. "Debt for nature swaps were first established in the 1980s in the attempt of solving two problems with one agreement: (1) Minimize the negative effect debt has on developing nations; (2) Minimize the environmental destruction that developing nations frequently cause". 
Beberapa contoh perkembangan pemanfaatan a debt-for nature swap di negara Dunia Ketiga (dikutip dari internet):

1. Ecuador. pertama kali melakukannya tahun 1989. "World Wildlife pioneered of debt-for nature-swap and successfully executed its first swap in Ecuador in 1989. Since then, WWF has played a vital role in the implementation of debt-for-nature wap around the world"

2. Bolovia. Given the size of Indonesia's foreign debt and the rate of forest destruction, "debt-for-nature swaps" seems an obvious solution. In these schemes, a portion of a nation's public debt is bought by a third party at substantial discount. The debt then is cancelled. In return, the country promise to protect severall million hectares of forests. Large conservation organizations like the US-based Conservation International, Rainforest Alliance and WWF have been actively promoting such transactions. The first "debt for nature" swap took place in 1987 in Bolovia. Since then, similar deals have been done in twenty countries, including Cost Rica, Ecuador, the Philippines and Madagascar (The Ecologist May-June 1992).

3. Panama. Ambassador Linda E. Watt announced April 8, 2003 that Panama had qualified for a U.S. government debt-for-nature program that will make at least \$5.6 million available for conservation of the Chagre National Park.

\section{Hasil Analisis}

\section{Penggunaan Swap untuk Membayar Utang Luar Negeri Indonesia}

\section{Utang Luar Negeri Indonesia}

Dapat dilihat pada Road Map Departemen Keuangan 4 Maret $2005^{4}$, target fiskal "rasio utang luar negeri" adalah menurun dari $25.30 \%$ pada tahun 2004 turun menjadi 12.60\% pada 2009 (lihat Tabel 1). Hal itu tentunya tidak akan tercapai by chance tetapi harus ada upaya yang sungguh-sungguh.

Tabel 1 RPJM: Target Fiskal

\begin{tabular}{lrrrrrr}
\hline (Dalam PDB tahun 2000) & \multicolumn{1}{c}{$\mathbf{2 0 0 4}$} & \multicolumn{1}{c}{$\mathbf{2 0 0 5}$} & \multicolumn{1}{c}{$\mathbf{2 0 0 6}$} & \multicolumn{1}{c}{$\mathbf{2 0 0 7}$} & \multicolumn{1}{c}{$\mathbf{2 0 0 8}$} & \multicolumn{1}{c}{$\mathbf{2 0 0 9}$} \\
\hline Defisit APBN & $-1.40 \%$ & $-1.00 \%$ & $-0.70 \%$ & $-0.30 \%$ & $-0.00 \%$ & $1.00 \%$ \\
Keseimbangan primer & $1.60 \%$ & $1.80 \%$ & $1.70 \%$ & $1.90 \%$ & $1.90 \%$ & $2.00 \%$ \\
Penerimaan pajak & $12.10 \%$ & $11.60 \%$ & $11.90 \%$ & $12.60 \%$ & $13.60 \%$ & $13.60 \%$ \\
Rasio utang Luar negeri & $25.30 \%$ & $21.60 \%$ & $19.30 \%$ & $16.70 \%$ & $14.40 \%$ & $12.60 \%$ \\
Rasio utang Dalam negeri & $28.60 \%$ & $25.30 \%$ & $24.60 \%$ & $22.80 \%$ & $21.00 \%$ & $19.20 \%$ \\
\hline
\end{tabular}

Sumber: Road Map Dep.Keu, Rapat Kerja Bapekki, 4 Maret 2005

Analisis a Debt-For-Nature Swap ... (Hinsa Siahaan) 
Pada Tabel 1 terlihat bahwa rasio utang luar negeri ditargetkan semakin menurun. Jika tahun 2004 rasionya adalah 25.60\% dari PDB tahun 2000 maka tahun-tahun berikutnya secara berturut-turut menurun menjadi $21.60 \%, 19.30 \%, 16.70 \%, 14.40 \%$, dan $12.60 \%$ pada tahun 2009.

Penurunan rasio utang luar negeri tersebut, pada hakikatnya dapat dicapai dengan dua cara. Pertama adalah dengan meningkatkan PDB secara signifikan dan menjaga agar jumlah utang luar negeri relatif konstan. Cara kedua adalah menekan jumlah utang luar negeri secara signifikan, yakni melunasi utang luar negeri tersebut sembari mempertahankan PDB tidak menurun. Pelunasan utang tersebut dapat dengan uang hasil pendapatan negara (dari tabungan pemerintah), dengan konsekuensi dana investasi untuk pembangunan ekonomi harus dikorbankan atau dapat juga dilakukan dengan "a debt-for-nature debt".

\section{Swap sebagai Upaya Pelunasan Utang Luar Negeri}

Untuk melakukan " $a$ debt-for-nature debt" pemerintah cq Departemen Keuangan terlebih dahulu menginventaris seluruh utang luar negeri, berapa jumlahnya, kapan jatuh temponya, negara mana krediturnya, apakah undang-undang pada negara kreditur membenarkan dan memungkinkan "a debt-for-nature debt” atau tidak. Seperti undang-undang di Jepang, tidak membenarkan adanya "a debt-for-nature debt”. Hal itu karena keputusan pertukaran utang negara dunia ketiga dengan hanya janji melindungi lingkungan hidup kepada negara kreditor dan parlemen pada negara kreditor kemungkinan menolaknya.

Langkah berikut pemerintah Indonesia cq Departemen keuangan harus mempersiapkan juru runding (Tim negosiator) untuk mendekati parlemen, seperti parlemen Jepang, agar Jepang bersedia menghapuskan atau minimal mengurangi utang Indonesia yang cukup dilunasi atau ditukar dengan hanya janji (komitmen) pemerintah Indonesia untuk senantiasa menjaga dan memelihara kelestarian alam Indonesia. Dalam hal ini, Tim negosiator apat menggunakan pendekatan dengan isu Millenium Development Goals (MDG).

Dengan swap, pemerintah tidak perlu mengeluarkan uang untuk mengurangi utang luar negeri. Uang yang seharusnya melunasi utang luar negeri tersebut dapat dibelanjakan pada barang alat investasi. Pemerintah akan fleksibel mengalokasikan pendapatan negara pada belanja barang modal yang produktif yang pada akhirnya diharapkan menghasilkan barang atau jasa dan menciptakan lapangan kerja yang sangat menentukan dalam peningkatan kesejahteraan rakyat Indonesia yang berkesinambungan. 


\section{PENUTUP}

\section{Simpulan}

Swap atau kesepakatan pertukaran antara uang dengan uang, tingkat bunga dengan tingkat bunga yang lazim digunakan oleh perusahaan swasta, dapat juga digunakan pemerintah negara dunia ketiga yang punya banyak utang kepada negara maju. Akan tetapi, dalam bentuk pertukaran utang dengan janji pemerintah untuk melestarikan lingkungan hidup, melindungi binatang buas, atau janji menghilangkan daerah kumuh di negara miskin yang banyak utang.

\section{Saran}

Karena penggunaan "a debt-for-nature swap" menguntungkan semua pihak, membuat semua pihak bahagia, dan memperhatikan pengalaman negara lain, pemerintah Indonesia cq Departemen Keuangan seyogianya harus optimis dapat menggunakannya secara optimal untuk mengurangi utang luar negeri. Sehingga, target untuk memperkecil rasio utang luar negeri Indonesia dari tahun ke tahun, sebagaimana ditargetkan dalam Road Map Departemen Keuangan, akan tercapai. Caranya adalah dengan mempersiapkan tim analisis utang luar negeri profesional dan team negosiator yang tangguh yang penuh dedikasi dan cinta tanah air. Team negotiator itu akan mengkaji utang luar negeri dan berunding dengan negara pemberi utang yang bersedia menghapuskan utang Indonesia dengan cara a debt-for-nature swap. 


\section{DAFTAR PUSTAKA}

Abimanyu, Anggito. Road Map Departemen Keuangan. Rapat Kerja Bapekki, 4 Maret 2005.

Allen, Steven L. and Arnold D. Kleinstein. 1991. Valuing Fixed Income: Investments and Derivative Securities. New York Institute of Finance.

Bisnis Indonesia. Jumat 13 Januari 2006.

Campbell, Tim S. 1988. Money and Capital Markets. Scott Foresman and Company.

Epping, Randy Charles. 1990. A Beginner’s Guide to The World Economy. Prentice-Hall.

Hady, Hamdy. 1998. Valas Untuk Manajer. Penerbit Ghalia Indonesia.

Hunt, Ben dan ChrisTerry. 1992. Financial Instruments and Markets. Robert Burton Printers Pty Limited.

Reynolds, Bob. 1987. Understanding Derivative. Pitman Publishing.

Schwartz, Robert J. and Clifford W Smith Jr. 1990. The Handbook of Currency and Interest Rate Risk Management. New York Institute of Finance.

Suara Pembaruan. Senin 16 Januari 2006.

\section{KUTIPAN}

2 Schwartz, Robert J. and Clifford W. Smith Jr. 1990. The Handbook of Currency and Interest Rate Risk Management. New York: Institute of Finance.

${ }^{3}$ Allen, Steven L. and Arnold D.Kleinstein. 1991. Valuing Fixed Income: Investments and Derivative Securities. New York: Institute of Finance.

${ }^{4}$ Abimanyu, Anggito. Road Map Departemen Keuangan. Rapat Kerja Bapekki, 4 Maret 2005. 